\title{
Experimental investigation of GTA Welded SS316L plates using shape memory alloy as a filler material
}

\author{
M. Naga Swapna $1{ }^{,}{ }^{*}$, Anusha Peyyala ${ }^{1}$, B. Purna Chandra Sekhar ${ }^{2}$, N. Venkata Krishna ${ }^{1}$ \\ ${ }^{1}$ Department of Mechanical Engineering, P V P Siddhartha Institute of Technology, Kanuru, Vijayawada, Andhra Pradesh, \\ India. \\ 2 Department of Mechanical Engineering, University college of Engineering and Technology, Acharya Nagarjuna \\ University, Guntur, Andhra Pradesh, India.
}

Global Journal of Engineering and Technology Advances, 2021, 06(03), 042-048

Publication history: Received on 23 January 2021; revised on 27 February 2021; accepted on 02 March 2021

Article DOI: https://doi.org/10.30574/gjeta.2021.6.3.0033

\begin{abstract}
Parameter optimization is the active subject of research, and in this current work the ferrite number and gas tungsten arc (GTA) welding SS. Filler material. Models have been developed by welding SD316L slab with NiTinol wire (shape memory alloy) as a filler material by conducting experiments using three-factor, three level factorial designs. Tests have been conducted for various models at UTM and the results are scheduled. The final models were upgraded using the design expert method. It can be seen from the investigation that the interactive effect of the process parameters has a significant effect on the tensile strength and the ferrite number.
\end{abstract}

Keywords: NiTinol; SS316L; GTA welding; Design Expert Optimization.

\section{Introduction}

Case tungsten arc welding (GTAW), often referred to as TIG welding, has become a popular choice of welding processes when high quality, precision welding is required. An arc is formed between the tungsten electrode, which is not consumed in TIG welding, and the metal is welded. Gas is supplied via a torch to protect the electrode and the molten weld pool. If filler wire is used, it is added separately to the weld pool. The SS31L material is low carbon and has a good weld strength factor. The ductility may decrease due to the increase in the carbon content of the steel, which improves the tensile strength and toughness of the steel. [1]. Buehler et al. [2] Alloy nitinol, first discovered, is named after the filler material used to make steel 316L alloy welding, based on NI for nickel, DI for titanium and NOL from the Naval Ordnance Laboratory. Nitinol presents many good properties such as superficiality, corrosion resistance and biocompatibility. Also the shape, stiffness and other properties of nitrite can be controlled by chemical composition, heat treatment and temperature [3] and Shabalovskaya et al., [4] Explored bio-compatibility and found its application in the form of stents and guide wires in medical devices. In recent years, nitinol has seen significant growth in eyeglass frames, cellular phone antenna, high pressure seal plug for diesel fuel injectors, and high temperature protection device for lithium ion battery. Although the possibility of its application in the welding medical equipment of the NiTi SMA has been extensively explored, research on the coupling of the NiTi SMAwith steel is currently limited. Li et al [5-6] conducted laser brazing of NiTi SMA and stainless steel with Ag-based filler metal, Capacitor discharge welding, microplasma arc welding done by Qiu [7] and laser welding done by Li [8] of NiTi SMA to stainless steel wires were investigated. However, further investigation on the dissimilar metal joining of NiTi SMA to stainless steel is necessary to explore the wider application of joint design. The two allotrophic changes of nitinol are martensitic and austenitic. The phases depend on the chemical composition, temperature and pressure. Chemical composition of steel 316L and

\footnotetext{
*Corresponding author: M.Naga Swapna, Email: mnagaswapnasri@gmail.com

Department of Mechanical Engineering, P V P Siddhartha Institute of Technology, Kanuru, Vijayawada, Andhra Pradesh, India. 
nitinol are given in Table 1. Thus the stainless steel with low carbon content is selected in order to have better parameters in welding.

Table 1 Chemical composition of SS316L and NiTinol

\begin{tabular}{|l|l|l|l|l|l|l|l|l|}
\hline & C & Co & Cr & Cu & Mn & Ni & Fe & Ti \\
\hline SS 316 L[wt\%] & 0.008 & 0.06 & 18.5 & 0.1 & 1.28 & 10 & Res & - \\
\hline Nitinol[wt \%/at\%] & - & - & - & - & - & $56 / 51$ & - & $44 / 49$ \\
\hline
\end{tabular}

In this paper, an attempt has been made to explore the precision welding process of TIGs with their tensile properties and ferrite number as a filler material for welding steel 316L slab with nitinol wire.

\section{Experimentation}

In the present study, different models are produced by different combinations of welding process parameters, i.e., welding current, welding speed and tip plate distance. The tests were performed on SS316L slabs with a thickness of 3 $\mathrm{mm}$, which were welded with $0.8 \mathrm{~mm}$ diameter NiTinol wire as a filler material between the butt joints. Important process control variables were identified and their upper and lower limits were identified. Selected values with units and symbols are given in Table 2.

Table 2 Process variables and their bounds.

\begin{tabular}{|l|l|l|l|l|l|}
\hline & units & notation & $\mathbf{- 1}$ & $\mathbf{0}$ & $\mathbf{1}$ \\
\hline Welding current & $\mathrm{amp}$ & $\mathrm{I}$ & 100 & 125 & 150 \\
\hline Welding speed & $\mathrm{mm} / \mathrm{min}$ & $\mathrm{S}$ & 140 & 160 & 180 \\
\hline Nozzle to plate distance & $\mathrm{mm}$ & $\mathrm{N}$ & 12 & 15 & 18 \\
\hline
\end{tabular}

Table 3 Design matrix and their responses

\begin{tabular}{|l|l|l|l|l|l|}
\hline $\begin{array}{l}\text { Experiment } \\
\text { runs }\end{array}$ & \multicolumn{3}{l}{ Process variables } & $\begin{array}{l}\text { Ferrite } \\
\text { Number }\end{array}$ & $\begin{array}{l}\text { Tensile } \\
\text { strength (MPa) }\end{array}$ \\
\hline & $\mathrm{N}(\mathrm{mm})$ & $\mathrm{I}(\mathrm{amps})$ & $\mathrm{S}(\mathrm{mm} / \mathrm{min})$ & & \\
\hline 1 & -1 & -1 & -1 & 0.54 & 389.98 \\
\hline 2 & -1 & 1 & -1 & 0.36 & 404.89 \\
\hline 3 & -1 & -1 & 1 & 0.51 & 388.76 \\
\hline 4 & -1 & 1 & 1 & 0.38 & 402.34 \\
\hline 5 & 1 & -1 & -1 & 0.52 & 389.23 \\
\hline 6 & 1 & 1 & -1 & 0.34 & 393.7 \\
\hline 7 & 1 & -1 & 1 & 0.53 & 388.54 \\
\hline 8 & 1 & 1 & 1 & 0.34 & 392.56 \\
\hline 9 & 0 & -1 & 0 & 0.55 & 388.89 \\
\hline 10 & 0 & 1 & 0 & 0.38 & 394.87 \\
\hline 11 & 0 & 0 & -1 & 0.41 & 391.32 \\
\hline 12 & 0 & 0 & 1 & 0.42 & 390.34 \\
\hline 13 & -1 & 0 & 0 & 0.44 & 391.34 \\
\hline 14 & 1 & 0 & 0 & 0.4 & 390.09 \\
\hline 15 & 0 & 0 & 0 & 0.45 & 390.78 \\
\hline 16 & 0 & 0 & 0 & 0.39 & 392.34 \\
\hline 17 & 0 & 0 & 0 & 0.45 & 391.34 \\
\hline 18 & 0 & 0 & 0 & 0.46 & 393.45 \\
\hline 19 & 0 & 0 & 0 & 0.37 & 390.54 \\
\hline 20 & 0 & 0 & 0 & 0.47 & 390.87 \\
\hline & & & & & \\
\hline
\end{tabular}


Three-factor, three-level test designs were selected to conduct the tests as shown in Table 3. Twenty test runs were conducted according to the design matrix. Traction strength FIE was measured with the help of a universal test machine and the ferrite number was measured with the help of FERITSCOPE FMP30 MACHINE and the relevant results were given using the design expert method for each process variables as shown in Table 3.

\section{Results and discussion}

In the present work, Models have been developed by welding SD316L plates using nitinol as a filler material by conducting experiments using three-factor, three-level factorial designs. Various samples were tested and the results are tabulated. An attempt has been made to investigate TIG's precision welding process for their tensile strength and ferrite number. Variation analysis (ANOVA) is performed to determine the significance of the process parameters for tensile strength and ferrite number. A mathematical model for tensile strength and ferrite number is developed and parameter optimization is performed. Finally the intermediate strength effects of the welding speed and the welding current are generated for the tensile strength and the ferrite number.

\subsection{Analysis of variance (ANOVA) of Tensile strength and Ferrite number}

The adequacy of the model so developed was then tested by using analysis of variance (ANOVA). The ANOVA table was constructed for both tensile strength and ferrite number as shown in Table 4 and 5.

Table 4 Analysis of variance for tensile strength.

\begin{tabular}{|l|l|l|l|l|l|l|}
\hline Source & $\begin{array}{l}\text { Sum of } \\
\text { squares }\end{array}$ & Df & $\begin{array}{l}\text { Mean } \\
\text { squares }\end{array}$ & F-value & $\begin{array}{l}\text { p- value } \\
\text { prob>F }\end{array}$ & \\
\hline Model & 318.25 & 9 & 35.36 & 15.31 & $<0.0001$ & Significant \\
\hline A-welding current & 184.56 & 1 & 184.56 & 79.9 & $<0.0001$ & \\
\hline B-welding speed & 4.33 & 1 & 4.33 & 1.87 & 0.2009 & \\
\hline $\begin{array}{l}\text { C-nozzle to plate } \\
\text { distance }\end{array}$ & 53.78 & 1 & 53.78 & 23.28 & 0.0007 & \\
\hline Residual & 23.10 & 10 & 2.310 & & & \\
\hline Lack of fit & 16.74 & 5 & 3.35 & 2.64 & 0.1556 & Not significant \\
\hline Cor total & 341.35 & 19 & & & & \\
\hline
\end{tabular}

Table 5 Analysis of variance for Ferrite number.

\begin{tabular}{|l|l|l|l|l|l|l|}
\hline Source & $\begin{array}{l}\text { Sum of } \\
\text { squares }\end{array}$ & Df & $\begin{array}{l}\text { Mean } \\
\text { squares }\end{array}$ & F- value & $\begin{array}{l}\text { p-value } \\
\text { prob>F }\end{array}$ & \\
\hline Model & 0.073 & 3 & 0.024 & 29.52 & $<0.0001$ & Significant \\
\hline A-welding & 0.072 & 1 & 0.072 & 87.34 & $<0.0001$ & \\
\hline B- welding & $1.000 \mathrm{E}-005$ & 1 & $1.000 \mathrm{E}-005$ & 0.012 & 0.9138 & \\
\hline $\begin{array}{l}\text { C- nozzle to } \\
\text { plate distance }\end{array}$ & $1.000 \mathrm{E}-003$ & 1 & $1.000 \mathrm{E}-003$ & 1.21 & 0.2878 & \\
\hline Residual & 0.013 & 16 & $8.272 \mathrm{E}-004$ & & & \\
\hline Lack of fit & $4.725 \mathrm{E}-003$ & 11 & $4.320 \mathrm{E}-004$ & 0.25 & 0.9276 & Not significant \\
\hline Cor total & 0.086 & 19 & & & & \\
\hline
\end{tabular}

The ANOVA analysis for tensile strength is given in Table 4. The model F-value of 15.31 indicates that the model is significant and the lack of fit is found to be insignificant. Welding current could be seen to have a major influence on tensile strength from tip to plate distance. The welding current shows a maximum contribution of 54.06\%, a welding 
speed of $1.26 \%$, and a tip-to-plate distance of $15.75 \%$. The p-value was also found to be less than 0.05 for welding reactions to current-tip plate distance. They account for $14.64 \%$. This gives a clear indication that the sample is adequate and can be associated with test data. This analysis was done with a 95\% confidence level. The "Lack of Fit F-value" of 2.64 indicates that the incompatibility is not significant compared to the pure error. There is a $15.56 \%$ chance of this major "Lack of Fit F-value" due to noise.

The ANOVA analysis for the ferrite number is given in Table 5. The f-value of 29.52 indicates that the sample is significant and the inconsistency is found to be negligible. Welding current could be seen to have a major influence on the ferrite number. The welding current shows the maximum contribution of $83.72 \%, 0.01 \%$ for the welding speed and $1.16 \%$ for the tip-to-plate distance. This gives a clear indication that the sample is adequate and can be associated with test data. This analysis was done with a 95\% confidence level. A "Lack of Fit F-value" of 0.25 indicates that the incompatibility is not significant compared to the pure error. There is a $97.26 \%$ chance of this major "Lack of Fit F-value" due to noise.

\section{Development of mathematical model for Tensile strength and Ferrite number}

The final mathematical models in coded form is determined with the help of DESIGN EXPERT 7.0 and are presented below :

$\mathrm{T}=407.90636+0.11322 * \mathrm{I}-0.45754 * \mathrm{~S}+1.38185^{*} \mathrm{~N}-4.45000 \mathrm{E}-004 * \mathrm{I} * \mathrm{~S}-0.033333 * \mathrm{I} * \mathrm{~N}+4.04167 \mathrm{E}-003 * \mathrm{~S} * \mathrm{~N}+$ $2.51927 \mathrm{E}-003 * \mathrm{I} 2+1.31136 \mathrm{E}-003 * \mathrm{~S} 2+0.045505 * \mathrm{~N} 2$

$\mathrm{Fn}=0.90250-3.40000 \mathrm{E}-003 * \mathrm{I}+5.00000 \mathrm{E}-005 * \mathrm{~S}-3.33333 \mathrm{E}-003 * \mathrm{~N}$

\section{Optimization of process parameters}

The optimization of the model is done using a design expert. A diagram for improving the answers Figure 1. Predictive values for welding current, welding speed and plate distance are found to be 1 . Since these values are similar, sample optimization is satisfactorily justified. The predictive value for tensile strength and ferrite number are found to be 0.933 and 0.907 , respectively. Because these values are close to similarity, model optimization is satisfactorily justified. The ten optimal solutions of the model and the associated factors are given in Table 6. High welding current of 150 amps, low welding speed of $140 \mathrm{~mm} / \mathrm{min}$ and low tip first plate distance of $12 \mathrm{~mm}$. Optimal values are appropriate for all work models.

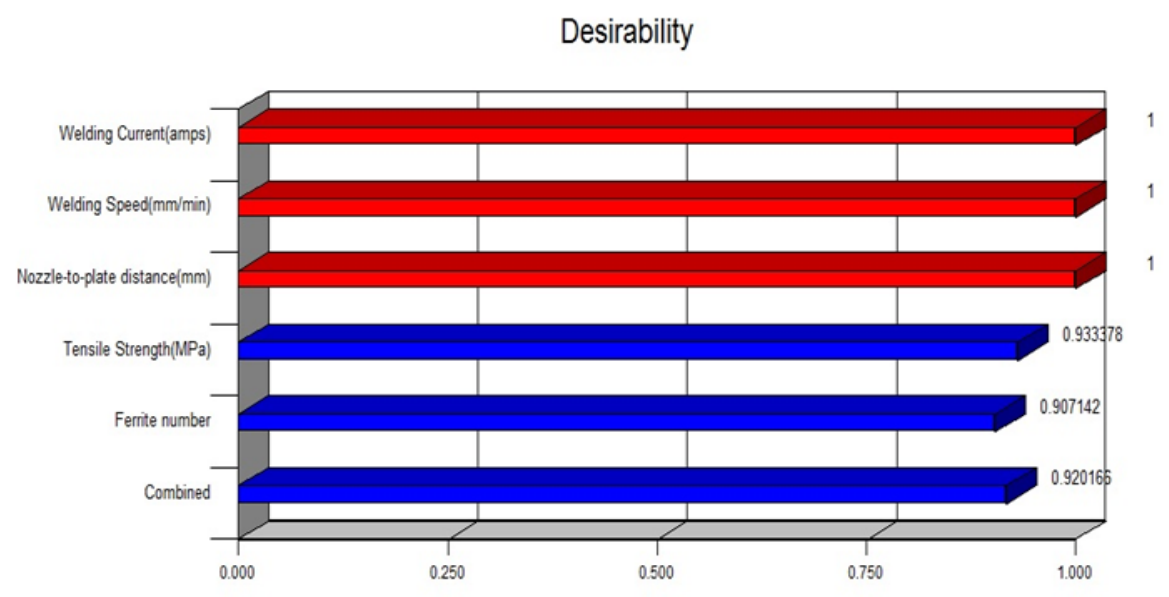

Figure 1 Optimization histogram of response

Based on these results, confirmation runs are made and the measured values of the answers are shown in Table 6. An average percentage error was calculated between the results of the optimal sample solutions and the stabilization runs. An error of $0.5 \%$ and $0.7 \%$ was found for the tensile strength and the ferrite number, respectively. Since these error values are less than uniform, the sample optimization is satisfactory and they can be used accurately to predict the answers. 
Table 6 Optimal solutions and confirmatory runs.

\begin{tabular}{|l|l|l|l|l|l|l|l|l|}
\hline Number & $\begin{array}{l}\text { Welding } \\
\text { current }\end{array}$ & $\begin{array}{l}\text { Welding } \\
\text { Speed }\end{array}$ & $\begin{array}{l}\text { Nozzle- } \\
\text { to-plate } \\
\text { distance }\end{array}$ & $\begin{array}{l}\text { Model } \\
\text { tensile } \\
\text { strength }\end{array}$ & $\begin{array}{l}\text { Exp } \\
\text { tensile } \\
\text { strengt } \\
\text { h }\end{array}$ & $\begin{array}{l}\text { Model } \\
\text { ferrite } \\
\text { numbe } \\
\text { r }\end{array}$ & $\begin{array}{l}\text { Exp } \\
\text { ferrite } \\
\text { number }\end{array}$ & Desirability \\
\hline 1 & 150 & 140 & 12 & 403.801 & 401.781 & 0.359 & 0.34 & 0.93 \\
\hline 2 & 150 & 140.09 & 12.04 & 403.714 & 402.623 & 0.359 & 0.34 & 0.92 \\
\hline 3 & 149.61 & 140 & 12 & 403.64 & 401.92 & 0.360 & 0.35 & 0.904 \\
\hline 4 & 149.20 & 140 & 12 & 403.47 & 403.12 & 0.362 & 0.35 & 0.904 \\
\hline 5 & 149.98 & 140 & 12.31 & 403.186 & 402.64 & 0.358 & 0.36 & 0.902 \\
\hline 6 & 150 & 145.63 & 12 & 403.23 & 401.24 & 0.359 & 0.36 & 0.90 \\
\hline 7 & 150 & 149.85 & 12 & 402.858 & 404.57 & 0.359 & 0.36 & 0.89 \\
\hline 8 & 150 & 152.04 & 12 & 402.68 & 405.76 & 0.360 & 0.37 & 0.884 \\
\hline 9 & 150 & 152.74 & 12 & 402.63 & 404.88 & 0.360 & 0.37 & 0.883 \\
\hline 10 & 150 & 155.42 & 12 & 402.43 & 404.24 & 0.37 & 0.36 & 0.876 \\
\hline
\end{tabular}

\section{Inter strengthation effects}

\subsection{Inter strengthation effects of welding speed and welding current on Tensile strength}

Figure 2 depicts the effect of welding speed ( $\mathrm{mm} / \mathrm{min}$ ) and tensile strength of the welding current (A). From this figure it is clear that the tensile strength increases with increasing welding speed with all levels of welding current. The tensile strength for different combinations of welding current and speed is shown in Figure 2, which shows that there is an increase in tensile strength when the welding current and speed increase together.

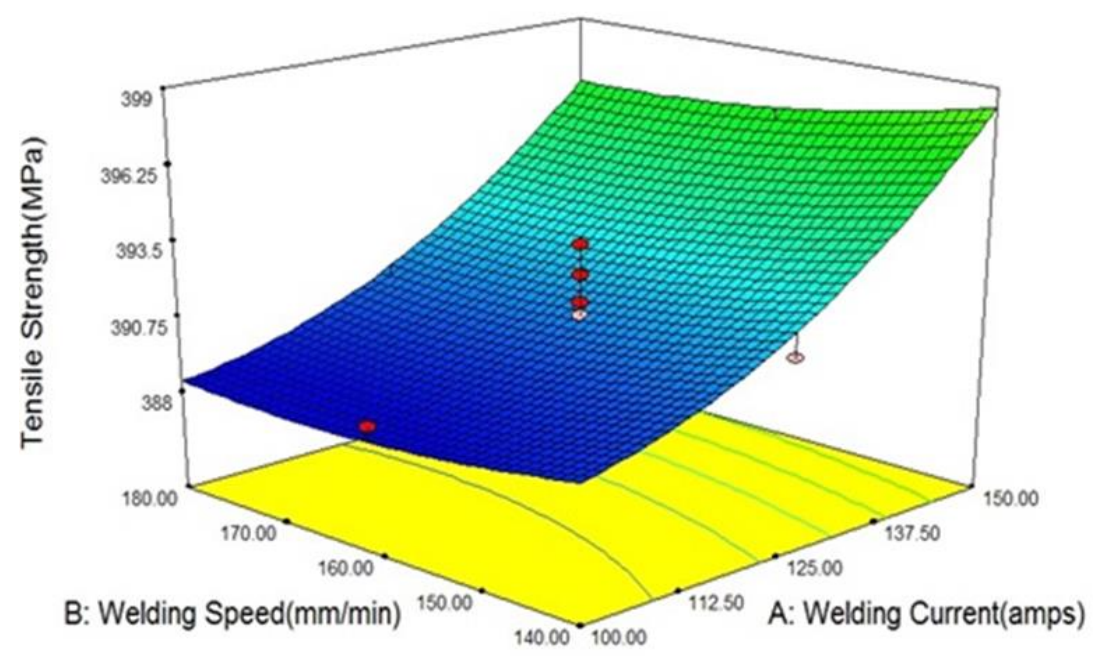

Figure 2 Surface plot for interaction effects of welding speed (mm/min) and welding current (amps) on Tensile strength (Mpa)

\subsection{Inter strengthation effects of welding speed and welding current on Ferrite number}

Figure 3 depicts the effect of welding speed ( $\mathrm{mm} / \mathrm{min}$ ) and tensile strength of the welding current (A). From this figure it is clear that the ferrite number decreases with increasing level of welding speed with all level welding current. The ferrite number for different combinations of welding current and speed is depicted in Figure 3 , which shows that the ferrite number decreases as the welding current and speed increase together. 


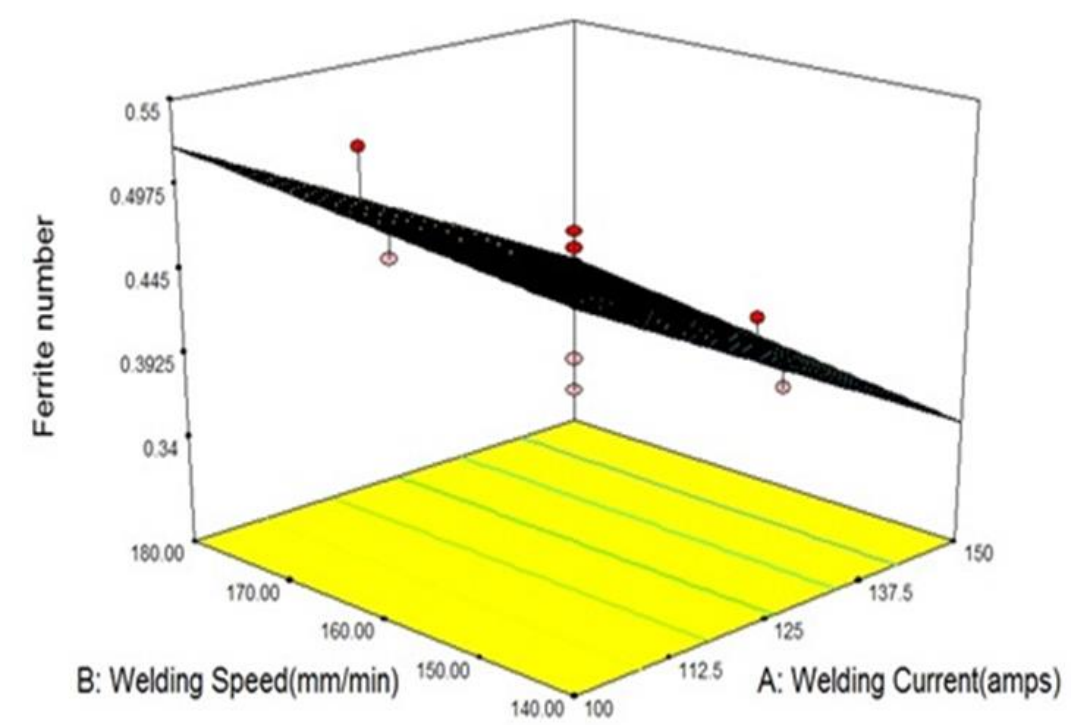

Figure 3 Surface plot for interaction effects of welding speed ( $\mathrm{mm} / \mathrm{min}$ ) and welding current (amps) on ferrite number.

\section{Conclusion}

- Experiments were conducted using the concept of DOE, and were used to create regression models using the response surface method with the help of Design Expert 7.0 software to find the optimal set of process parameters.

- Tensile strength was found to increase with increasing welding speed ( $\mathrm{mm} / \mathrm{min}$ ) and welding current (amps).

- The ferrite number was found to decrease with increasing welding speed ( $\mathrm{mm} / \mathrm{min}$ ) and welding current (amps).

- The optimization of the selected design is shown in the ten best solutions and stabilizing runs. The average error percentage between the model and the test runs was found to be less than the similarity.

\section{Compliance with ethical standards}

\section{Acknowledgments}

Authors would like to thank SAGTE for sponsoring in carrying out this work.

\section{Disclosure of conflict of interest}

All authors declare that they have no conflict of interest.

\section{References}

[1] Uenishi K, Seki M, Kunimasa T, Takatsugu M, Kobayashi KF, Ikeda T, Tsuboi A. "YAG laser micro welding of stainless steel and shape memory alloy [J]". Proceedings of SPIE. 2003; 4830: 57-62.

[2] Buehler WJ, Wang FE. A summary of recent research on the Nitinol alloys and their potential application in ocean engineering. Ocean Engineering. 1968; 1: 105-108.

[3] Weiss B, Stickler R. Phase instabilities during high temperature exposure of 316 austenitic stainless steel Metallurgical and materials transactions. 3(4): 851-866.

[4] Shabalovskaya SA. Surface, corrosion and biocompatibility aspects of Nitinol as an implant material [J]. BioMedical Materials and Engineering. 2002; 12: 69-109.

[5] Li MG, Sun DQ, Qiu XM, Sun DX, Yin SQ. Effects of laser brazing parameters on microstructure and properties of TiNi shape memory alloy and stainless steel joint [J]". Materials Science and Engineering A. 2006; 424: 17-22. 
[6] Li MG, Sun DQ, Qiu XM, Sun DX, Yin SQ. Microstructures and properties of capacitor discharge welded joint of TiNi shape memory alloy and stainless steel [J]". China Welding. 2005; 14(2): 95-100.

[7] Qiu XM, Sun DQ Li MG, Liu WH. Microstructures and properties of welded joint of NiTi shape memory alloy and stainless steel [J]". Transactions of Nonferrous Metals Society of China. 2004; 14(3): 475-479.

[8] Li HM, Sun DQ, Han YW, Dong P, Liu C. Microstructures and mechanical properties of laser-welded TiNi shape memory and stainless steel wires [J]". China Welding. 2010; 19(3): 1-5.

\section{Author's short biography}

\begin{tabular}{|l|l|}
\hline & $\begin{array}{l}\text { Dr. M. Naga Swpana Sri did her Ph.D in Meta Metal Composites area with a total of } 11 \text { years of } \\
\text { Teaching Experience. }\end{array}$ \\
\hline & $\begin{array}{l}\text { Dr. P. Anusha did her Ph.D in Refrigeration \& Air Conditioning area with a total of } 10 \text { years of } \\
\text { Teaching Experience. }\end{array}$ \\
\hline
\end{tabular}

